\title{
21
}

\section{A Continuous Simulation Approach for Separate Sewered Areas}

\author{
Mark D. Loehlein, Terry J. Meeneghan and Timothy Prevost
}

The demand for large-scale watershed and sewershed planning studies in the United States has been increasing steadily over the past ten years. In large part, the demand is driven by major government programs regulating combined sewer overflows (CSO), sanitary sewer overflows (SSO), and storm water discharges. The implementation of these regulatory programs often results in local or regional public agencies embarking upon large multi-year studies requiring a comprehensive inventory of watershed and sewershed infrastructure, a characterization of the hydrologic and hydraulic function of that infrastructure, and analyses into the mechanisms by which pollutants are discharged into receiving waters. Significant monetary investments are made into comprehensive field investigations and surveys, hydrologic and hydraulic models, and regional facilities planning to develop and implement short- and long-term CSO and SSO control strategies.

Accurately determining the quantity of extraneous flow that enters public sewers and private service laterals is a critical component of these comprehensive studies. The amount of rainfall dependent inflow and infiltration (RDII) entering the separate sewer systems varies from site to site and event to event as precipitation over a sewershed may produce different RDII responses within the sewers at different times of the year. The Lower Ohio hydrologic and hydraulic modeling project in Pittsburgh, Pennsylvania provided a unique opportunity to improve upon the accuracy and reliability of model simulations by incorporating monthly variations in sewer system responses to rainfall events. The completed analyses and model implementation were successful in quantifying site specific and seasonal variations observed in RDII responses.

Loehlein, M., T. Meeneghan and T. Prevost. 2005. "A Continuous Simulation Approach for Separate Sewered Areas." Journal of Water Management Modeling R223-21. doi: 10.14796/JWMM.R223-21.

(C) CHI 2005 www.chijournal.org ISSN: 2292-6062 (Formerly in Effective Modeling of Urban Water Systems. ISBN: 0-9736716-0-2) 
This chapter will discuss the innovative technical refinement of accounting for site specific, seasonal variations in sewer system responses to rainfall events in hydrologic/hydraulic modeling efforts.

\subsection{Background Information}

The ALCOSAN Authority: ALCOSAN serves the City of Pittsburgh and all or part of 82 other municipalities in the region. The Authority provides wastewater conveyance and treatment to a service area of approximately 310 square miles $\left(800 \mathrm{~km}^{2}\right)$ and a service population of approximately 823,000 people. ALCOSAN maintains 90 miles $(144 \mathrm{~km})$ of interceptor sewers, which includes both deep tunnel and shallow-cut interceptors, and a 225 million gallon per day (mgd) (850 million liters per day) secondary wastewater treatment plant, which ultimately will be expanded to $875 \mathrm{mgd}$. Along the interceptor system are over 300 regulator structures that intercept dry weather flow and control wet weather flow into the ALCOSAN system. ALCOSAN does not have jurisdiction over the collection systems, which are owned and operated by the individual municipalities. The ALCOSAN authority is in the process of refining and implementing a Regional Long Term Wet Weather Control Plan (RLTWWCP) to control CSO and SSO discharges into area water bodies. It has been estimated that the cost for ALCOSAN and its satellite service communities to implement this plan could be as high as $\$ 3$ billion (US dollars). Approximately $\$ 1$ billion would be invested during the first 10 to 15 years of plan implementation and the remainder spread over a 50 y period. Opportunities to reduce this cost are largely dependent upon the refinement of the hydrologic and hydraulic characterization of combined and separate sewer systems within the region, the refinement of the control facilities design process, and the municipalities working together.

The Lower Ohio Study Area: The Lower Ohio basin is located in the northwest portion of the ALCOSAN service area and was used as the study area to demonstrate the effectiveness and accuracy of the simulation approach. The watershed comprises an area of approximately 16.5 square miles $\left(43 \mathrm{~km}^{2}\right)$ and contains a service population of approximately 48,200 who reside in 15 municipalities. For the sewered portions of the basin, combined sewers serve approximately $9 \%$ of the basin area while approximately $91 \%$ consists of separate sanitary sewered areas. A map of the Lower Ohio study area is provided on Figure 21.1. 


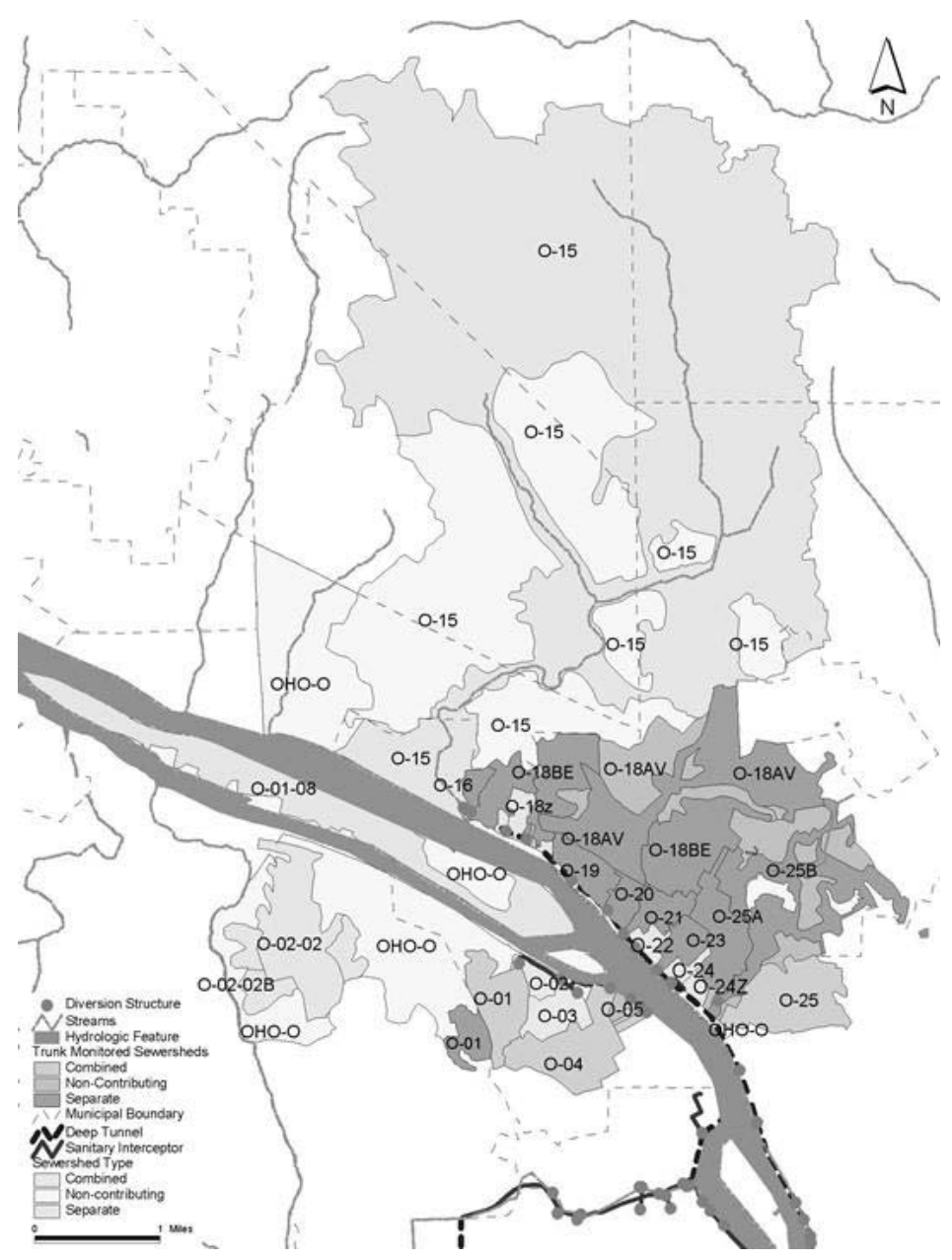

Figure 21.1 Lower Ohio Study Basin and monitored sewersheds used for analysis.

\subsection{Data Sources}

For the development and refinement of the Lower Ohio hydrologic and hydraulic models, RDII relationships were needed to represent the hydrologic contributions from the separate sewered areas directly. Wet weather flows 
from the separate sewered areas in the Lower Ohio basin are controlled by the precipitation entering the municipal collection systems and customer service laterals through RDII. The quantity of RDII entering the municipal collection sewers and customer service laterals determines the quantity of wet weather flow entering the ALCOSAN Lower Ohio interceptor system. Two key data sources were required for developing the RDII relationships: (i) a large quantity of temporally and spatially distributed precipitation data and (ii) a large quantity of quality reviewed, accurate and reliable sewer flow monitoring data.

Precipitation Data: A calibrated radar-rainfall system was implemented in April 2000 to monitor precipitation (rainfall and snowfall) within the greater Pittsburgh region. The system is owned and operated by the Three Rivers Wet Weather Demonstration Program (3RWWDP), who made the investment to implement the system with the belief that improved precipitation estimates could significantly reduce the ultimate cost for regulatory compliance. The radar-rainfall system utilizes a geo-referenced $1-\mathrm{km}^{2}$ pixel grid with 872 pixel squares required to cover the entire ALCOSAN service area and 2,313 needed to provide coverage over all of Allegheny County. The system is currently supported by a network of 33 heated precipitation gauges installed at an average density within the ALCOSAN service area of one gauge per 15 square miles $\left(40 \mathrm{~km}^{2}\right)$. For larger storms meeting a specified criterion, radarbased precipitation data is provided for each pixel contained on the grid. For smaller storms not meeting the criteria, gauge data is 'filled' using the inverse-distance-squared method to provide a continuous precipitation record for each pixel cell. The precipitation data is provided to engineers, municipalities, and other interested individuals via an Internet site maintained by 3RWWDP and was used as the precipitation input into the hydrologic/ hydraulic models and supporting analyses.

Wastewater Flow Monitoring Data: The ability to derive the RDII relationships in the separate sewered areas and assess the accuracy of the hydrologic/hydraulic models was dependent upon the availability of accurate and reliable monitored wastewater flow data. Beginning in March 2002, a network of monitors was deployed within the Lower Ohio basin to provide the required depth and flow data at various key locations. Three broad categories of sewer flow monitoring were conducted in support of the model and the Lower Ohio study: regional monitoring along the ALCOSAN interceptor, sewershed monitoring along municipal combined sewers near the point of connection with the ALCOSAN system, and monitoring of separate sewered areas near the point of connection with the ALCOSAN system. As part of this monitoring program, eight individual separate sewersheds were monitored continuously for a minimum of one year. The metering activities allowed for the quantification of the total influent municipal flow from the 
separate sewered areas to the points of connection with the Lower Ohio interceptor system. A total of 115 meter-months of data were collected with 46 individual storm events gathered from each of the eight separate sewersheds. Prior to its use in subsequent analyses, the flow monitoring data underwent a comprehensive quality review program to ensure that the data collected were accurate and reliable. The Lower Ohio study area and corresponding monitored separate sewered areas are shown in Figure 21.1.

\subsection{Extraneous Flow Quantification Process}

RDII is extraneous flow that is present in sewer systems during and after storm events. RDII quantities tend to increase rapidly during a storm, and then dissipate gradually to seasonal base flow levels over the next few days after an event. Ground water infiltration (GWI) is extraneous flow, present during both dry-weather and storm events and enters a sewer system and/or service lateral connection from the ground through system defects. The accurate quantification of GWI and RDII is important to the development and refinement of the hydrologic/hydraulic models that support the ALCOSAN RLTWWCP because excessive RDII can limit the net available conveyance capacities in sewers and increase the frequency and duration of sewer backups and $\mathrm{CSO} / \mathrm{SSO}$ discharge activity.

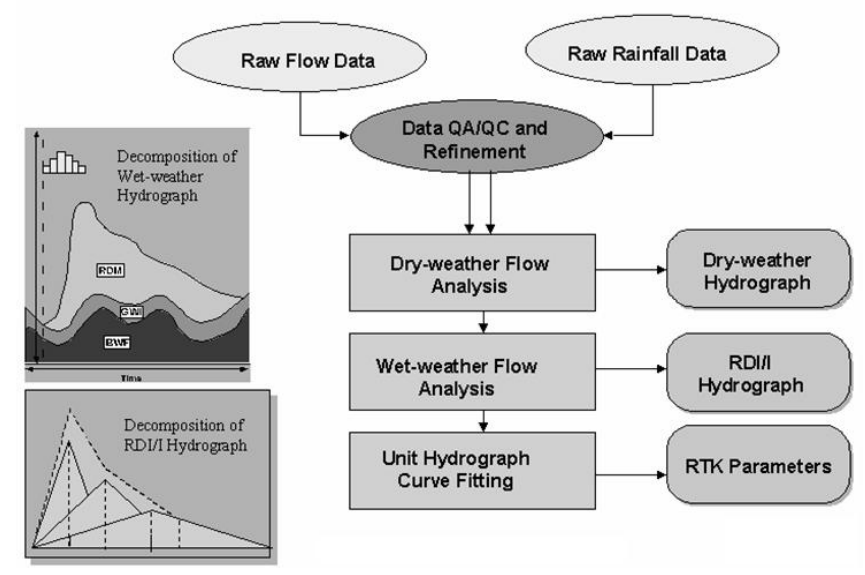

Figure 21.2 Illustration of the RDII analysis process. 
Unit hydrograph curve fitting analyses allowed for the determination of characteristic relationships between precipitation and RDII within the separate sewered areas of the Lower Ohio basin. The goal in analyzing the flow monitoring data collected in the separate sewered areas of the basin was to simulate RDII response from observed rainfall using three triangular unit hydrographs. For the monitoring data available, the analyses were performed using the SHAPE Utilities Programs - a proprietary program of CDM used to analyze wastewater flow monitoring data. The five-step procedure that was used to perform the RDII analyses on the monitored data is shown on Figure 21.2 and described in the following paragraphs.

Flow Data Preparation: In the flow data preparation process, the monitored data was entered into the SHAPE Utilities Program and reviewed for completeness, proper formatting, and compatibility with the requirements of the subsequent RDII analysis processes. The review also included error checking, identifying data gaps, and filling in periods of missing data.

Precipitation Data Preparation: To quantify RDII, there must be a corresponding rainfall data point for each wastewater flow data point. In the precipitation data preparation process, calibrated radar-rainfall data from each of the pixel cells located with the Lower Ohio basin were area-weighted to provide continuous precipitation data for individual sewersheds. The 'sewershed rainfall' data sets were then entered into the SHAPE Program and reviewed to confirm that they were complete and met the requirements of the RDII analysis process.

Dry-Weather Flow Evaluations: After the data entry, format conversions, and reviews of the flow and precipitation data had been completed, dryweather flow analyses determined the typical diurnal pattern for the sum of base wastewater flow (BWWF) and GWI. The analyses consisted of identifying days within the monitoring period of record that were not affected by a rainfall event. The methodology also eliminated other atypical days in which the dry-weather flows may have been affected by holidays or other special events. The monitored diurnal patterns for the selected dry-weather days were averaged together. Average weekday and weekend dry-weather flow hydrographs were computed and used in subsequent hydrograph decomposition processes to determine the RDII flows during rainfall events.

Wet Weather Flow Analyses: The average daily dry-weather flow (ADDWF) hydrographs calculated by the program were then used to quantify RDII volumes for each of the storms that occurred during the analysis period by a process called hydrograph decomposition. The first step in the analysis was to manually adjust GWI rates to account for seasonal variations. The seasonal adjustments were based on the assumption that the difference between monitored flows and the computed ADDWF hydrograph should be approximately zero before and after a storm. RDII volumes and peak flows 
for individual storm events were calculated by subtracting the seasonally adjusted dry-weather flow hydrograph (wastewater plus GWI) from the total monitored flow (wastewater plus GWI plus RDII). An illustrative example of hydrograph decomposition can be seen on Figure 21.3.

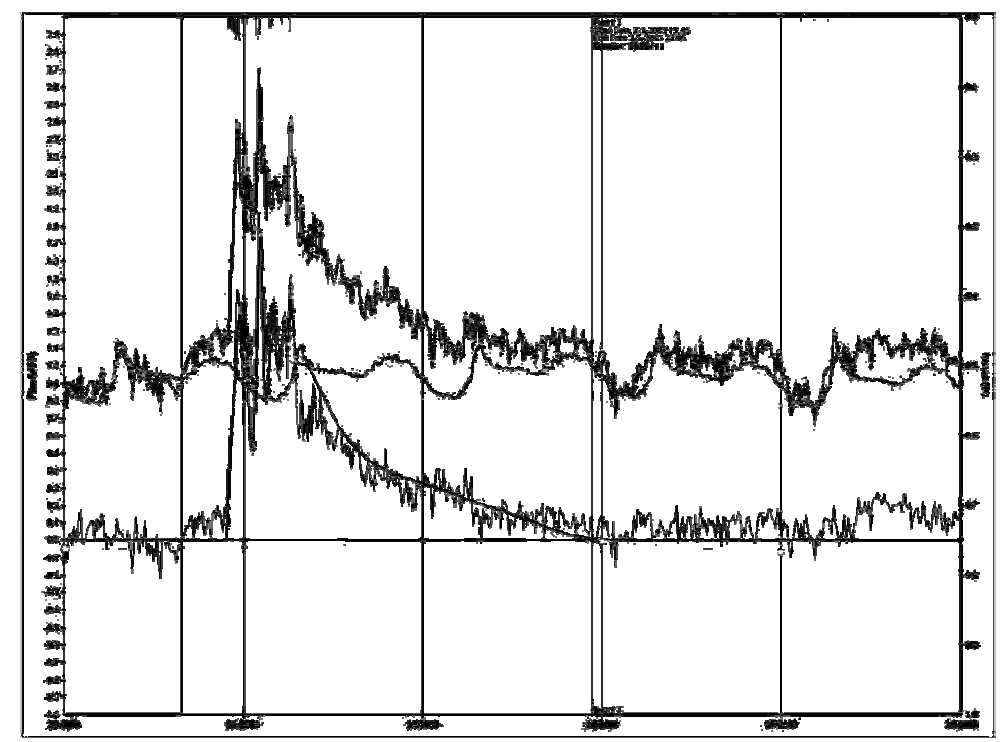

Figure 21.3 Example of hydrograph decomposition.

The top line is the monitored wastewater flow, the total of the BWWF, GWI, and RDII components. The bottom lines are the BWWF and seasonally adjusted GWI components. The second line from the top is the computed RDII hydrograph, calculated by subtracting the BWWF and GWI components from the total monitored wastewater flow. For each monitored storm, the total rainfall volume over the monitored sewershed area, the storm-induced RDII volume, and the total $\mathrm{R}$-value were computed. The total $\mathrm{R}$-value is defined as the ratio of the calculated RDII volume to the rainfall volume over the sewered area, expressed as a percentage. For example, an R-value of 0.08 indicates that $8 \%$ of the total observed rainfall volume that fell over the sewershed area made its way into the sewer system as monitored RDII.

Unit Hydrograph Curve Fitting: The unit hydrograph curve fitting segment of the analysis process allowed for the determination of a characteristic relationship between rainfall and RDII for each metering 
location. Unit hydrograph parameters were developed through a systematic analysis of measured flow and rainfall.

Figure 21.4 illustrates how the RDII is characterized from an observed rainfall intensity of ' $I$ ' under this approach. Each unit hydrograph is characterized by the following three parameters:

- $R$ - the fraction of the rainfall volume that enters the sanitary sewer system

- $\quad T$ - the time from the onset of the rainfall to the peak of the RDII hydrograph (in hours)

- $K$ - the ratio of the time to recession of the RDII hydrograph to the time to peak

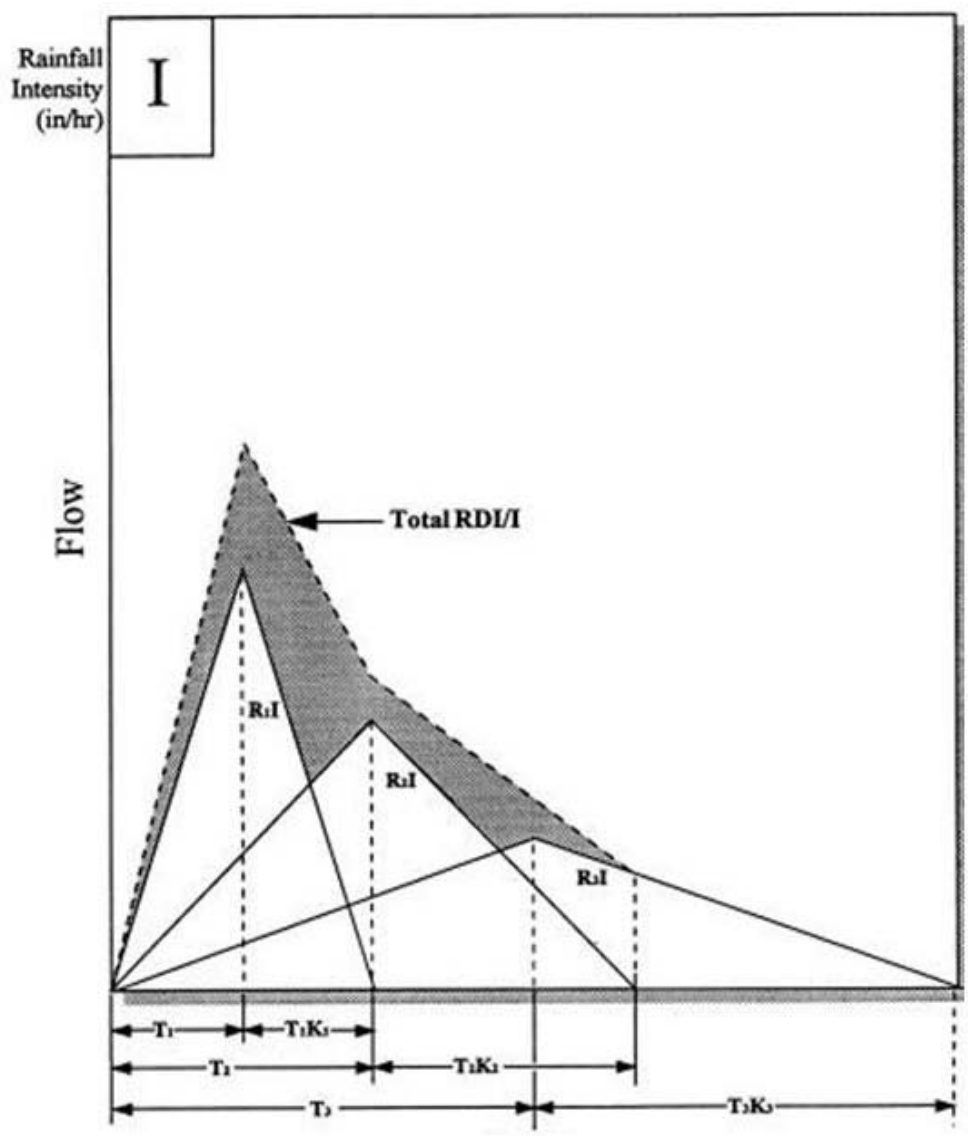

Figure 21.4 Illustration of unit hydrograph curve fitting. 
The goal of the unit hydrograph curve fitting process was to adjust the $R, T$, and $K$ parameters for each event analyzed to obtain a reasonable fit. $R T K$ values were adjusted so, when applied to monitored precipitation data, the simulated RDII matched the monitored wastewater flow. During the process, it was expected that the $R T K$ parameters will vary from event to event; generally being higher for wet antecedent moisture conditions and lower for dryer antecedent moisture conditions.

\subsection{Lower Ohio Basin Case Study and Model Application}

The Lower Ohio unit hydrograph curve fitting analyses were carried out so that values for $R T K$ parameters for every event during the monitoring period were determined and the RDII response of the sewershed for each individual storm was accurately represented (as illustrated in Figure 21.4). Once the curve fitting for all the storm events for the Lower Ohio monitoring sites was completed, the end result was individual sets of $R T K$ values that define the three triangular unit hydrographs used to simulate the RDII response of the sewer systems for each individual event. Also calculated during the analyses were the total $R$ for each simulated storm, the percentage difference between the simulated and the monitored total $R$, the peak wet weather flow simulated by the three hydrographs for each storm, and the percentage difference between the simulated and the monitored wastewater flow peak for each storm.

After the unit hydrograph curve fitting for individual storm events was completed, all of the events for a particular site were put together. Two alternative approaches were then considered for input into the RUNOFF module of the United States Environmental Protection Agencies (USEPA) Storm Water Management Model (SWMM): (i) average the individual storms into one composite set of RTK values, (ii) average the storms for each individual month to develop a set of monthly-varying $R T K$ parameters. The latter approach was chosen as the method used for the representation of the RDII responses of the Lower Ohio separate sewered areas in SWMM.

The average value of the $R, T$, and $K$ parameters for events occurring in a given month were calculated. Care was taken not to include those events that had unusually large or small values, i.e. were not representative of the sewershed response for a given month of a given site. The end result of the curve fitting analyses was a set of monthly-varying $R T K$ parameters for each 
of the monitored separate sewersheds in the Lower Ohio basin. These sets of parameters were then entered into the RUNOFF model and used in the model calibration of the separate sewered areas. This approach allowed for the monthly variation in wet weather responses to be accounted for in model simulations beyond the monitoring period. As displayed in Section 21.5, this monthly variation was found to be significant in the sewersheds that were analyzed as the RDII responses during the winter and spring months were found to be significantly higher than those observed during other seasonal periods. By not accounting for the monthly-varying responses, and applying a 'fixed' system response instead, the model simulation results for periods beyond the monitoring period would be less accurate and reliable.

\subsection{Analysis Results}

Using the unit hydrograph curve fitting method, all the storms from each of the monitored separate sewersheds in the Lower Ohio basin were simulated to match individual event RDII responses. This process resulted in the RTK parameters for individual storms which were then translated into sets of monthly-varying RTK parameters. Figures 21.5 and 21.6 show the results for two selected sewersheds that were analyzed. These figures show a marked variation of total R, R1, R2, and R3 over the months of a year.

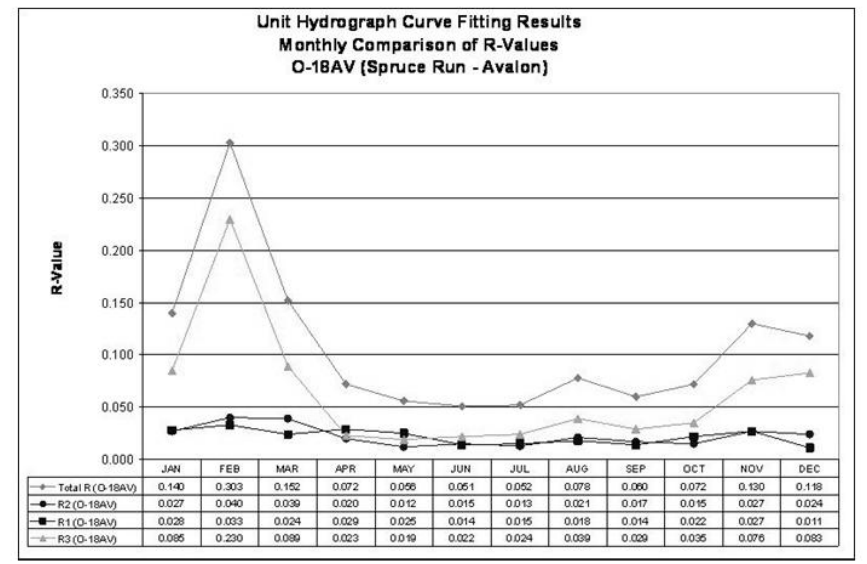

Figure 21.5 Monthly-varying parameters for sewershed O-18AV.

As these figures (and other analyzed sites) show, the amount of RDII entering the separate sewer systems varies with the site, the event, and the season of the year. Precipitation over a sewershed showed to produce different RDII responses within the sewers at different times of the year. A 
consistent pattern of higher RDII volumes during the winter and early spring months and lower volumes during the summer months was observed at all locations analyzed. The completed analyses were successful in quantifying site specific, and seasonal variations observed in RDII responses.

By accounting for the seasonal variability in RDII response, the analysis proved to enhance the performance and accuracy of the Lower Ohio Tier-2 model. This was demonstrated by a comparison study, supported by $40+$ events analyzed for each monitoring location that evaluated the RUNOFF model results using the monthly variable $R T K$ values against the results using a 'fixed' system response that remained constant throughout the year.

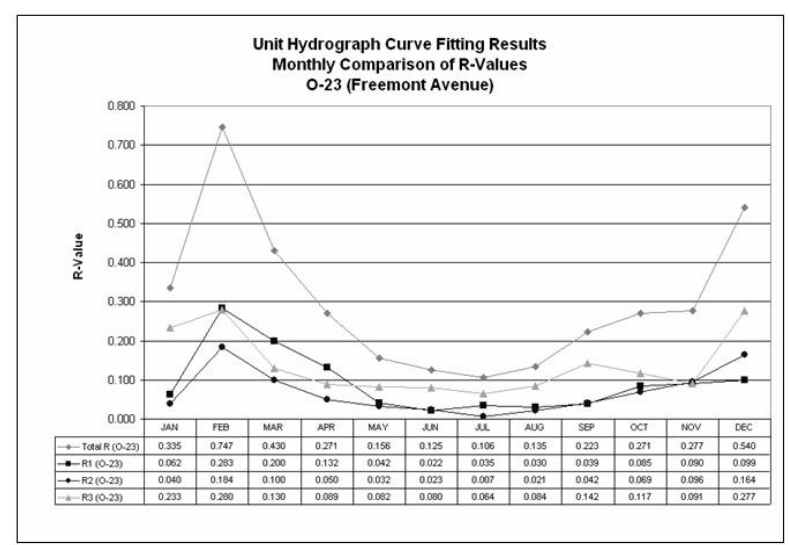

Figure 21.6 Monthly-varying parameters for sewershed O-23.

Figures 21.7 and 21.8 show a comparison of these results as they relate to storm event volumes for a selected analyzed site. Figure 21.7 shows a comparison regression plot of the observed event volumes (in million gallons) on the $x$-axis and the simulated event volumes using a 'fixed' system response on the $y$-axis. The solid line on the plot represents the regression line while the dashed line shows the line of equal fit. The resulting slope of the regression line is 0.611 and the corresponding $R^{2}$ is 0.570 . Figure 21.8 shows a comparison regression plot of the observed event volumes on the $\mathrm{x}$-axis and the simulated event volumes using the monthly variable $R T K$ values on the $y-$ axis. The resulting slope of the regression line is 0.934 and the corresponding $R^{2}$ is 0.953 .

These results show that the use of a 'fixed' system response would reduce the accuracy and reliability of the model as the event volumes for the winter 
and spring storms would be under-predicted while the volumes for the summer events would be over-predicted. The results using monthly-varying RTK parameters improved the performance and accuracy of storm volumes.

A similar comparison analysis was conducted that evaluated storm event peaks using the monthly variable $R T K$ values against the results using a 'fixed' system response. Figure 21.9 shows a comparison regression plot of the observed event peaks (in mgd) on the $x$-axis and the simulated event peaks using a 'fixed' system response on the $y$-axis.

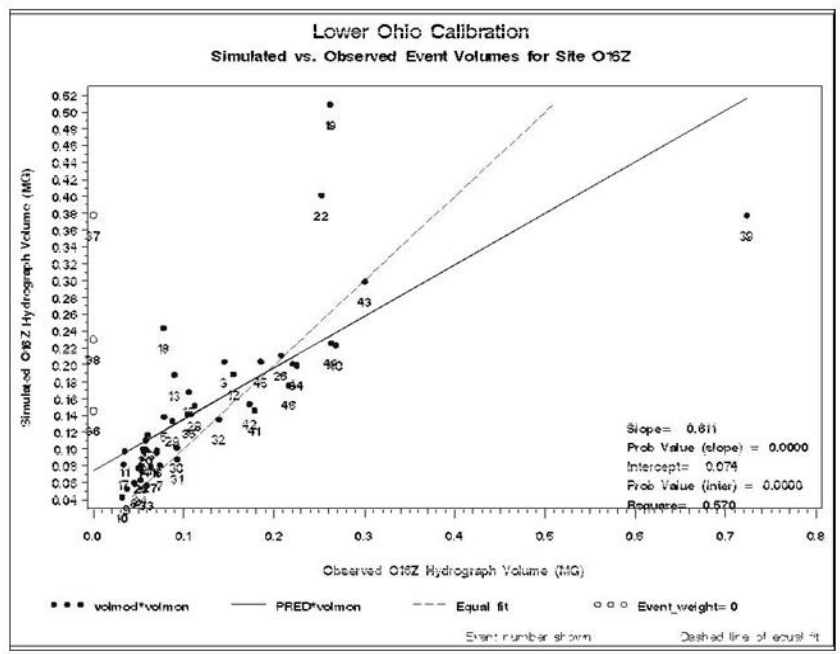

Figure 21.7 Regression for 'fixed' system response for Site O-16Z (vol).

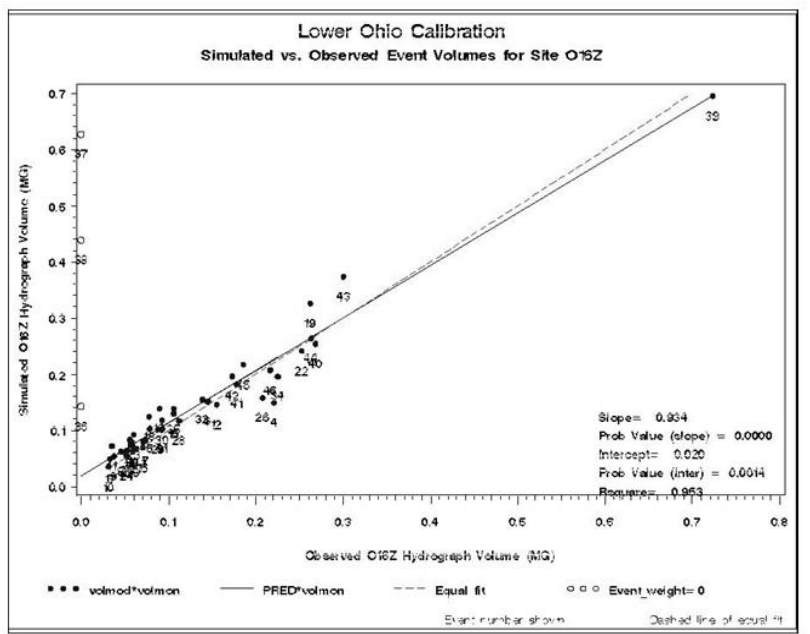

Figure 21.8 Regression for RTK parameters for Site O-16Z (vol). 


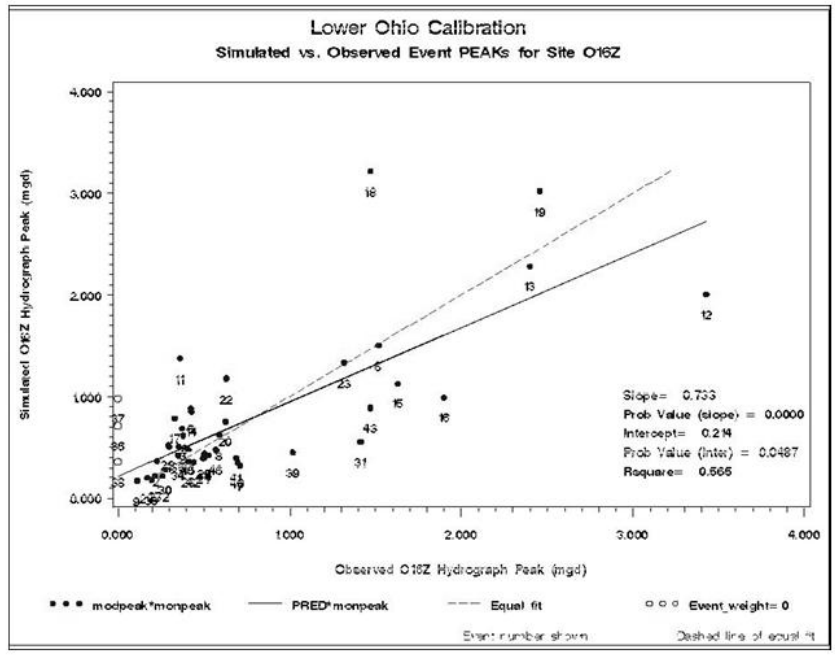

Figure 21.9 Regression analysis results using a 'fixed' system Response for Site O-16Z (peaks).

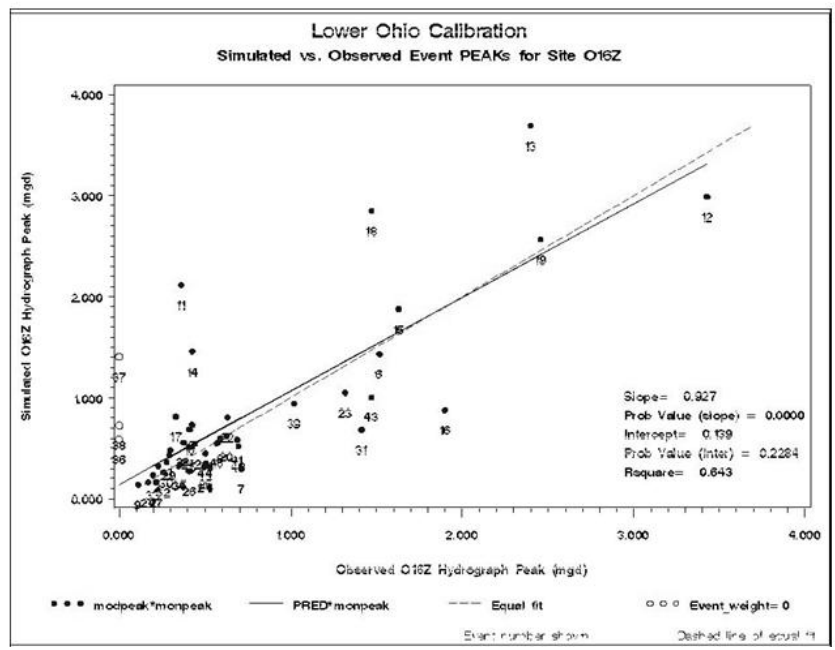

Figure 21.10 Regression analysis results using variable $R T K$ parameters for Site O-16Z (peaks). 
The solid line on the plot represents the regression line while the dashed line shows the line of equal fit. The resulting slope of the regression line is 0.733 and the corresponding $R^{2}$ is 0.565 . Figure 21.10 shows a comparison regression plot of the observed event peaks on the $x$-axis and the simulated event peaks using the monthly variable $R T K$ values on the y-axis. The resulting slope of the regression line is 0.927 and the corresponding $R^{2}$ is 0.643 thus proving that the use of monthly-varying $R T K$ parameters also improves the model's accuracy with simulating storm peaks.

\subsection{Conclusions}

In the greater Pittsburgh region, the ALCOSAN authority and its 83 tributary service communities have made a significant investment to develop and refine the RLTWWCP that is intended to control CSO and SSO discharges into area receiving waters. Significant investments were and are still being made to better inventory and characterize regional wastewater conveyance and treatment systems, municipal collection systems, and private service laterals. Complex hydrologic/hydraulic models have been prepared and are being refined and improved to better quantify and characterize extraneous groundwater and storm water flow in sewer systems and the corresponding frequency and duration of CSO/SSO discharges. The model refinement of using monthly varying $R T K$ parameters greatly enhanced the performance and accuracy of the complex models. This conclusion is supported below.

The large quantity of accurate and reliable precipitation and flow monitoring data, collected over an extended monitoring duration, allowed for a more complete characterization of RDII responses in separate sewer systems. Typically, for many modeling projects, a limited number of monitored storms are available for model calibration, and this necessitates assuming and using a "fixed" sewer system response that is constant throughout the year. The large number of monitored storms collected over $12+$ months for the Lower Ohio basin allowed for the use of monthly-varied sewer system responses. The high resolution, spatially-varied calibrated radarrainfall data that was available, when used in conjunction with the flow metering data, allowed for the accurate quantification of RDII responses in the separate sewer systems.

Monthly varied $R T K$ parameters allowed for seasonal variability in RDII responses to be accounted for: The quantity of RDII finding its way into separate sewer systems was found to vary from site to site, event to event, and season of the year. Precipitation over a sewershed should produce different RDII responses within the sewers at different times of the year. A consistent pattern of higher RDII volumes during the winter and early spring months and 
lower volumes during the summer months was observed at all of the locations analyzed. The completed analyses were successful in quantifying site specific, seasonal variations observed in the RDII response. The high-resolution simulation technique was successful in characterizing a wide variety of sewershed types.

The analysis approach allowed for the various types of separate sewersheds in the study basin to be characterized: The network of trunk sewer monitors served as the principal source of information for quantifying dry and wet weather flows conveyed by municipal sewer systems and private service laterals to the ALCOSAN interceptor system. The data were used to develop an understanding of the hydrologic and hydraulic response of municipal sewersheds to drought, storms, seasonal groundwater changes, and snowmelt. The wet weather analysis approach applied to the data allowed for the characterization of storm-induced extraneous flows that are discharged from the municipal collection sewers to the ALCOSAN system.

Monthly varied RTK parameters allowed for more accurate model simulations: The modeling approach of using three triangular unit hydrographs to simulate RDII responses in separate sewers is used in the more technically advanced national sewer modeling studies. This approach is further enhanced with the new innovation of applying monthly variable RTK values to represent the wet weather response from separate sewered areas. Based on an independent comparison study that was conducted that evaluated the model simulation results using the monthly variable RTK parameters against the results using a 'fixed' system response, it was proven that this innovative advancement improved the accuracy and reliability of our model simulation results.

\section{References}

Brater, E.F., "The Unit Hydrograph Principle Applied to Small Watersheds”, Amer. Soc. Civ. Eng, vol 105, pp 1154-1178

Chow, V.T., Handbook of Applied Hydrology, Sec. 14, McGraw Hill, New York

Curtis, David C., and Rod Thornhill, "Use of Radar and Rain Gauge Estimates in Inflow / Infiltration Analyses to Improve Remediation Recommendations", presented at the AWRA 34th Annual Conference, Mobile, AL, November 19, 1998

Dooge, J.C.I., "A General Theory of Unit Hydrograph", Journal of Geophysical Research, 64(2), pp 241-256, 1959

Jonnalagadda, Krishna, "Determination of Instantaneous Unit Hydrographs for Small Watersheds", University of Houston, February 2003 
Straub, Timothy D., Melching, Charles S., and Kocher, Kyle E., "Equations for Estimating Unit Hydrograph Parameters for Small Rural Watersheds", United States Geological Survey, Urbana, IL, 2000 